\title{
O altar \& o trono: dinâmica do poder em $O$ alienista
}

Ivan Teixeira. [Cotia: Ateliê Editorial; Campinas: Editora da Unicamp, 2010, 432 p.]

A um só tempo, $O$ altar \& o trono, de Ivan Teixeira, deu prosseguimento, em nível metodológico, aos seus trabalhos de análise literária e inaugurou uma via interpretativa bastante profícua nos estudos machadianos. Quem conheceu os estudos realizados por Ivan Teixeira - que, pelos caprichos da vida, prematuramente faleceu em 2013 - saberá avaliar a continuidade do seu trabalho de análise e história literárias ali praticado. No meio acadêmico, Ivan Teixeira ficou conhecido sobretudo por suas incursões em objetos literários do período colonial. Sua tese de doutorado, sob a orientação de João Adolfo Hansen, foi publicada sob o título de Mecenato pombalino e poesia neoclássica (1999), tendo havido relevante reconhecimento por pesquisadores desse período, com a conquista de dois prêmios importantes: Lasa Book Prize (EUA) e o Prêmio Jabuti, ambos no ano 200o. Antes disso, Teixeira já havia demonstrado rigor interpretativo em sua arguta análise sobre O Uraguay, de Basílio da Gama.

É curioso notar que os trabalhos com Machado de Assis ocupam na vida intelectual de Ivan Teixeira um lugar de destaque antes mesmo do seu ingresso na carreira de docente na universidade. Em 1987, ainda estudante de pós-graduação, ele é responsável por escrever o livro Apresentação de Machado de Assis. O contato inicial e a primeira publicação pelo crítico de uma obra sobre o escritor brasileiro o qualificam para outros voos na obra machadiana. $\mathrm{O}$ apreço às primeiras edições de livros e aos periódicos literários, além de demonstrar a bibliofilia levada a sério, levou Teixeira a se tornar um exímio organizador de edições de obras de nossa literatura e da literatura portuguesa. Criterioso no trabalho filológico, o crítico se tornaria responsável pelo preparo de algumas edições da obra de Machado, tais como Dom Casmurro, em 1988, e Papéis avulsos, em 2005.

De certa maneira, o livro $O$ altar \& o trono demarca todos esses territórios de preocupações e demonstra o intenso trabalho de pesquisa documental e a erudição pertinente, esta já conhecida de outros trabalhos. Resultado de sua tese de livre-docência defendida, em 2009, na Escola de Comunicações e Artes da Universidade de São 
Paulo, a obra em questão é fruto de pesquisas de longa data do crítico, com divulgações periódicas desde os anos 1990.

Se fosse possível sintetizar em frase curta a contribuição desse livro para nossa crítica literária, seria o caso de dizer que essa obra realiza uma espécie de materialização do autor Machado de Assis, em sua ligação com escritores, intelectuais e as formas discursivas em circulação em seu tempo. O enfoque adotado foi investigar a novela $O$ alienista, publicada de forma seriada pelo escritor brasileiro entre outubro de 1881 e março de 1882, nas edições de A Estação e publicada em Papéis avulsos, no final do ano de 1882 .

Torna-se pertinente perguntar: como $O$ altar \& o trono recompõe as muitas vozes presentes em $O$ alienista?

Procurando identificar como essa novela constrói nexos entre a forma literária e a própria vida social, Ivan Teixeira cria linhas mestras para o seu trabalho investigativo, as quais podem ser assim delineadas: (1) o diálogo histórico contemplado em $O$ alienista; (2) as fontes intertextuais dessa narrativa em relação aos discursos científicos de sua época, aos discursos retórico-políticos em circulação nos tempos de sua produção e difusão e aos trabalhos de autores de fora do país, a exemplo de Poe, Teofrasto, La Bruyère, Swift, entre outros; (3) o processo de consagração de Machado de Assis, que soube, estrategicamente, aliar de dentro do seu campo artístico e intelectual a feitura de narrativas muito bem elaboradas com formas de inserção, por meio de periódicos, dos seus trabalhos escritos em distintos gêneros textuais. Seria, nesse contexto, uma estratégia machadiana a preferência pelo "conto e pelo capítulo curto", num tipo de "adequação da arte ao espaço físico do jornal".

Distante de uma crítica, por assim dizer, mais idealista, cuja premissa básica é a universalidade indiscutível - senão genial - do escritor brasileiro no mais alto panteão literário, o exame proposto por Ivan Teixeira evidencia uma outra condição do célebre autor carioca: Machado de Assis, na escritura de seu O alienista, esteve intimamente ligado às condições de produção de um discurso ficcional dentro de um periódico jornalístico, de tal modo que o crítico aventou a hipótese de que, à mesma época, de elaboração e publicação dessa novela em A Estação, Machado possa ter sido editor literário desse jornal. Implícita a esta hipótese está uma ideia central no processo interpretativo de Teixeira, segundo a qual a novela seria também uma caricatura jornalística de sua época, representando um compromisso do escritor com o periódico em questão.

Dentro da fortuna crítica de $O$ alienista, o livro de Teixeira se distingue por 
alguns aspectos em relação aos trabalhos já publicados sobre a obra. Embora o crítico reconheça a figuração da loucura, em sua chave de leitura humorística, e a ironização da autoridade e da centralização do poder como questões pertinentes numa possível leitura da novela, ele oferece ao leitor uma nova base interpretativa para $O$ alienista, cuja síntese é assim descrita: "Assim, apoiado no motivo da loucura, o tema central da novela seria a disputa pelo poder no processo de formação da cidade, e não propriamente $o$ exame de uma situação de força previamente estabelecida" (p. 19).

É o caso de se perguntar: que disputa representada é esta?

Partindo da hipótese de que exista uma forma alegórica plasmada em O alienista, para Ivan Teixeira essa novela machadiana "alude a discursos mais específicos e com mais nitidez na cultura de seu momento de circulação" (p. 20). É preciso esclarecer, por sua vez, que o crítico não, necessariamente, compreende, nem tampouco busca legitimar, que essa novela machadiana seja resultante tão só de uso esquemático e sumário do acontecimento histórico. Talvez seja mais do que isso. O ensaísmo de $O$ altar \& $o$ trono julga não ser obra do acaso a publicação de O alienista em A Estação. De acordo com a poética cultural do seu tempo, a novela teria sido elaborada conforme diretriz presente no periódico. O princípio ordenativo do texto machadiano, com cortes precisos e com a opção por escritos de menor volume como o conto, seria também tributário da própria dinâmica do veículo.

No caso de $O$ alienista, o crítico aponta que a resposta de base alegórica e humorística está desencadeada por três conjuntos de eventos marcantes no Segundo Reinado, a saber: (1) as disputas entre o Estado e a Igreja, cujo resultado se acompanha pelos desdobramentos da Questão Religiosa, ocorrida entre 1872 e 1875; (2) o estabelecimento sistemático da medicina psíquica no período, levando, em 1841, à criação do Hospício de Pedro Segundo; (3) as revoltas próprias do Período Regencial, quase sempre abafadas pelo poder centralizador do Império. A primeira dessas séries de eventos parece constituir o ponto mais original da abordagem contemplada em $O$ altar \& o trono, e será mais à frente objeto de nossa incursão mais específica.

Por ora, é preciso compreender melhor as bases metodológicas adotadas nessa obra. Inspirada nos estudos de Stephen Greenblatt, um dos principais nomes do New Historicism norte-americano, a locução poética cultural designa na obra de Ivan Teixeira o seu método interpretativo do texto literário. Essencialmente, essa forma de análise propalada pelo crítico está preocupada em delinear com rigor e critério as muitas camadas de significação presentes nos objetos culturais, sob a égide de dois aspectos principais: nas formas do discurso artístico, na maneira como estão configuradas por 
processos de constante ressignificação e intercâmbio com a sociedade de onde emergem, e na forma da cultura - entendida como uma "estrutura geradora de sentido" - e o seu conjunto de signos. Não à toa, é nessa cultura, rica de textos, manifestações, movimentações e gêneros discursivos distintos, que

[...] os objetos, os registros, as instituições e os códigos ultrapassam o valor de uso para atingir a condição de símbolo, de metáfora, de índice ou alegoria. Associa-se à constituição dos padrões, sistemas e linguagens. Nesse corpo de múltiplas representações, nada será unívoco e isolado, porque tudo resulta de operações de troca e mobilidade (p. 28).

Nesse horizonte de preocupações metodológicas, o estudo de poética cultural na leitura de $O$ alienista tem a especificidade de inventariar e investigar as linhas de força presentes no debate em que a obra se insere. Para isso, foi imperativo que o crítico conferisse especial atenção às formas de estruturação da obra, atentando ainda para a relação da narrativa, em termos de intercâmbio e mobilidade, com outros textos participantes nas disputas de um campo cultural em ebulição. Se, para Ivan Teixeira, a literatura pode ser concebida "como intervenção artística em determinada controvérsia cultural", é porque o lugar da singularidade de um texto literário, para ele, está na compreensão da modulação geral de sua estrutura e na delimitação criteriosa das disputas específicas de que este texto é participante ativo na sociedade de seu tempo.

Sua visão, que em certa medida poderia, sob os auspícios dos escritos de Mikhail Bakhtin, ser considerada de base dialógica, centra o estudo do texto literário em sua relação com outros textos e outros discursos do seu tempo. O pressuposto é de que haveria, incondicionalmente, um universo de referências ligado ao texto, cabendo ao escritor a mediação e o trabalho não com fatos históricos, mas, sim, com o que o crítico chama de "poética dos fatos", reconhecida como as formas de representações de um amplo universo da história cultural de cada época.

A diretriz crítica presente em $O$ altar \& o trono retoma a novela de Machado de Assis para configurá-la em seu ambiente de circulação original, o jornal A Estação. Numa chave de leitura polêmica, Teixeira se contrapõe a dois críticos machadianos consagrados - Lúcia Miguel Pereira e Roberto Schwarz. Se para estes dois há uma "intrínseca superioridade" do célebre escritor brasileiro em relação aos demais escritores contemporâneos, restando a ele escrever para um público que pouco compreendia a real dimensão de sua literatura, para Ivan Teixeira, Machado estaria plenamente integrado ao seu público, inclusive o de periódico. Especificamente, no caso de A Estação, 
o crítico aponta que as narrativas machadianas ali publicadas participariam significativamente do projeto editorial desse periódico. Veja-se sua constatação para O alienista:

Se a configuração gráfica do jornal (figurinos coloridos, gravuras de arte, pórtico neoclássico da primeira página) pode ser interpretada como vitória de um conjunto conhecido de valores, $O$ alienista propõe uma alternativa sarcástica contra a rigidez dessas mesmas certezas, sugerindo as nuanças da ironia e do humor (p. 65).

Não menos polêmica é a hipótese (já antes enunciada) levantada por Ivan Teixeira, cujos argumentos sustentam que Machado de Assis se tornara no jornal um editor da chamada "Parte Literária". O raciocínio que suporta essa hipótese está relacionado à aparição de textos específicos de Machado em A Estação, de modo que tal prática seria, necessariamente, evidência de um envolvimento que ultrapassava em larga escala a figuração de um simples colaborador. De alguma maneira, atrelada a essa ideia se encontra outra. A opção em $O$ alienista em privilegiar a sátira menipeia estaria também ligada às formas de ajuste da narrativa a esse jornal. Conforme o crítico aponta, "tratava-se de fazer o texto parecer com o jornal, com o leitor e com o tempo de sua produção" (p. 141).

A composição de $O$ altar \& o trono faz também uma boa alternância nas discussões entre as fontes de diálogos com autores estrangeiros e autores nacionais. $\mathrm{Da}$ língua inglesa e da língua francesa, variadas são as assimilações realizadas por Machado de Assis, configurando um espectro de diálogos que se estende de La Bruyère a Edgar Allan Poe.

Todavia, uma fonte parece se destacar na interpretação do crítico. Refiro-me ao filósofo e retor grego Teofrasto e sua tradição do caráter. Salvo engano, Ivan Teixeira é o primeiro pesquisador a realizar um estudo mais sistemático sobre essa tradição na obra machadiana. Antes dele, Sônia Brayner, num prefácio à antologia O conto de Machado de Assis (1981), havia chamado a atenção para essa evidência.

Conforme as premissas desenvolvidas no estudo, o crítico não esteve preocupado com a demonstração de que Machado possa ter sido um leitor de Teofrasto, ainda que no acervo pessoal do escritor brasileiro, na Academia Brasileira de Letras ( $\mathrm{ABL}$ ), exista um exemplar de Os caracteres, em tradução do grego realizada por La Bruyère; mas em inventariar possíveis traços estilísticos e de uso da técnica literária advindos dessa tradição retórica. Machado de Assis, em sua obra, não explicita as referências a La Bruyère, tampouco a Teofrasto, fato que não invalida, para o crítico, a hipótese de 
que a composição de todas as personagens em O alienista são formas delineadas a partir da tradição do caráter, pois para ele:

[...] há evidência, em sua ficção, de que adota o processo compositivo do caráter. Resulta daí a conviç̧ão de que leu o autor grego na versão francesa de la Bruyère, sendo admissível supor também que se tenha familiarizado com a técnica do gênero em outros escritores, como Plutarco, Swift, Sterne ou Fielding - todos praticantes do caráter e citados nos escritos machadianos (p. 164).

Considero um dos pontos altos do livro de Ivan Teixeira o capítulo homônimo ao título da obra. É nele que o crítico formaliza, de modo mais agudo, sua singular interpretação sobre essa novela machadiana. Uma das passagens dessa interpretação gravita em torno da conhecida e histórica Questão Religiosa - a disputa entre o trono, representado por d. Pedro II, e o clero, cuja figura hierárquica de maior monta é o papa Pio IX. O ensaísta constata, antes de mais nada, a circulação de dois discursos, demarcadamente, contra o avanço da Igreja e do clero frente ao Estado e às instituições brasileiras do período. Se o primeiro desses discursos é considerado "sisudo, doutrinário e administrativo", o outro discurso é muito mais caricatural e, por assim dizer, mais satírico. Segundo o ponto de vista contundente de $\mathrm{O}$ altar \& o trono, foi a esta última forma de discurso que Machado se filiou para a construção de $O$ alienista, preferindo para tanto as nuanças irrepetíveis da caricatura a se instalar no valor mais doutrinário. A dimensão interpretativa lançada pelo ensaísta, além de contemplar um trabalho investigativo do modus construtivo do texto machadiano, busca trazer um olhar que perscrute a narrativa em seu ambiente original, com a produção seriada em periódico e a circulação num jornal com um público leitor da segunda metade do século Xıx.

Nesse sentido, O alienista, incorporando o "discurso da caricatura anticlerical" do período em insinuações de todas as ordens, é considerado pelo crítico uma intervenção que apoia a renovação institucional em curso no país. Cabe uma passagem significativa desse ponto de vista:

Especificando um pouco mais, estou convicto de que $O$ alienista incorpora o pensamento ilustrado da década anterior, colocando-se a seu modo, contra a doutrina de Pio IX e, sobretudo, contra a intromissão da Igreja na organização política da cidade, o que se representa na novela pela ironia aos artifícios empregados pelo padre Lopes para controlar o recolhimento das pessoas à Casa Verde. Não se trata de defender a reclusão dos 
supostos loucos como solução ficcional para os impasses sociais da cidade ou para os desafios técnicos da ciência. Trata-se, ao contrário, de enfatizar que, na trama imaginária do texto, as reclusões de Bacamarte devem ser interpretadas como símbolos de atitudes regeneradoras em tempos de domínio da desrazão generalizada [...] (p. 298).

Por fim, convém ressaltar que o livro de Ivan Teixeira tem o mérito de aproximar, no campo da análise literária, dois aspectos: a pesquisa documental em diferentes arquivos, no Brasil e no exterior, e a interpretação literária com critério, rigor teórico e analítico e imaginação crítica. É preciso ainda apontar a pesquisa iconográfica integrada à obra. Sem que se constitua um efeito tão somente acessório à obra, as imagens no livro ganham caráter informativo e participam, significativamente, no jogo argumentativo do crítico.

Com $O$ altar \& o trono, Teixeira se firmou como um legítimo machadiano; não por acaso, foi aclamado na casa de Machado e obteve premiação da ABL. Trata-se de obra que, dentro da fortuna crítica do autor de Dom Casmurro, vem renovar as formas metodológicas no tratamento dos discursos mobilizados em narrativas machadianas. Enfim, uma resposta convincente, tal como nosso grande escritor merece.

Arlindo Rebechi Junior é professor no Departamento de Ciências Humanas da Faculdade de Arquitetura, Artes e Comunicação da UNESP, atuando nos cursos de graduação e de pós-graduação. Doutor em Literatura Brasileira pela Universidade de São Paulo. 